\title{
Intrapartum Care Working Patterns of Midwives: The Long Road to Models of Care in Germany
}

\section{Intrapartale Hebammenbetreuung: Ein langer Weg zu Betreuungsmodellen in Deutschland}

Authors

Mechthild M. Gross ${ }^{1}$, Claire Michelsen ${ }^{1}$, Bernhard Vaske ${ }^{2}$, Sonja Helbig ${ }^{1}$

\author{
Affiliations \\ 1 Midwifery Research and Education Unit, Hannover \\ Medical School, Hannover, Germany \\ 2 Institute for Biostatistics, Hannover Medical School, \\ Hannover, Germany
}

Key words

models of care, midwifery, Germany, caseload midwifery, midwife led care

Schlüsselwörter

Betreuungsmodelle, Hebammentätigkeit, Deutschland, Hebammengeleitete Betreuung

received 05.07 .2017

accepted 01.11.2017

Bibliography

DOI https://doi.org/10.1055/s-0043-122888

Published online: 2018

Z Geburtsh Neonatol

(c) Georg Thieme Verlag KG Stuttgart · New York

ISSN 0948-2393

Correspondence

Prof. Dr. Mechthild M. Gross, RM RN BSc MSc

Midwifery Research and Education Unit

Hannover Medical School

Carl-Neuberg-Straße 1

30625 Hannover

Germany

Gross.Mechthild@mh-hannover.de

\section{ABSTRACT}

Introduction Midwifery models of care help to enhance perinatal health outcomes, women's satisfaction, and continuity of care. Despite the ubiquitous presence of certified midwives at births in Germany, no research has investigated the diversity of midwives' practice patterns. Describing the variety of working patterns through which midwives provide intrapartum care may contribute to improving the organisation of midwifery services.
Methods This cross-sectional survey took place in the region of Hannover and Hildesheim, Germany. Midwives attending births and practicing in hospitals and/or out-of-hospital were able to participate. Midwives who did not attend births were excluded. We assessed midwives' scope of services, practice locations, employment patterns, continuity of care, midwife-led births, and midwives' level of agreement with core values of midwifery care. The response rate of the survey was $32.7 \%(69 / 211)$.

Results We found that midwifery care services can be described according to midwives' employment patterns. The majority of midwives were employed in a hospital to provide intrapartum care $(74.2 \%, n=49)$, and most also independently offered one or more antenatal and/or postpartum service/s. Only $25.8 \%(n=17)$ of midwives offered their services independently (laborist model of care). Independent midwives attended births in all three possible settings: hospital, free-standing birth centres and home. Significantly more independent midwives than employed midwives offered antenatal care and lactation consulting. Compared to employed midwives, significantly more independent midwives provided antenatal, intrapartum, and postpartum care to the same women, were more likely to know women before labour, and to offer one-to-one care during labour.

Discussion The most common practice pattern among surveyed midwives was 'employment in a hospital' for provision of intrapartum care with additional postpartum and few antenatal services provided on an independent basis. Midwives who worked solely independently reported more continuity and one-to-one intrapartum care with women. Most midwives did not work in patterns that offered continuity of care or consistently provide one-to-one care. Future research should assess whether women in Germany desire more services similar to caseload midwifery.

\section{ZUSAMMENFASSUNG}

Einleitung Hebammenbetreuungsmodelle fördern das peripartale Gesundheitsergebnis, die mütterliche Zufriedenheit sowie die Betreuungskontinuität. Trotz der allgegenwärtigen Präsenz von zertifizierten Hebammen bei Geburten in 
Deutschland, wurden die vielfältigen Arbeitsstrukturen von Hebammen noch nicht untersucht. Ziel dieser Studie war es, Arbeitsstrukturen von Hebammen zu beschreiben, um einen Beitrag zur Verbesserung der Hebammendienstleistungen aufzuzeigen.

Methoden Die Querschnittserhebung wurde in der Region Hannover und Hildesheim, Niedersachsen, durchgeführt. Hebammen, die Geburten betreuten und in Krankenhäusern und/ oder außerhalb von Krankenhäusern tätig waren, konnten teilnehmen. Hebammen, die keine Geburten betreuten, wurden aus der Studie ausgeschlossen. Beurteilt wurden das Leistungsspektrum, der Arbeitsplatz, die Arbeitsbedingungen, die Betreuungskontinuität und die Übereinstimmung von Hebammen mit zentralen Zielen der Hebammentätigkeit. Die Rücklaufquote der Studie lag bei 32,7\% (69/211).

Ergebnisse Hebammenbetreuung konnte am ehesten in Verbindung mit den Arbeitsstrukturen beschrieben werden. Der Großteil der Hebammen war im Krankenhaus angestellt und betreute dort Gebärende (74,2\%, n=49). Darüber hinaus boten die meisten Hebammen selbstständig Leistungen der Schwangerenvorsorge oder des Wochenbetts an. Nur 25,8\%
( $n=17)$ der Hebammen waren alleinig freiberuflich tätig. Freiberufliche Hebammen begleiteten Geburten an allen drei möglichen Geburtsorten: Im Krankenhaus, im Geburtshaus und Zuhause. Im Vergleich zu angestellten Hebammen boten signifikant mehr freiberuflich tätige Hebammen Schwangerenvorsorgen und Stillberatungen an und betreuten ein und dieselben Frauen sowohl vor, während als auch nach der Geburt, kannten die Schwangeren eher vor der Geburt und boten öfter eine Einszu-eins- Betreuung während der Geburt an.

Diskussion Unter den befragten Hebammen war das verbreitetste Betreuungsmodell die Anstellung im Krankenhaus zur Betreuung von Geburten im Krankenhaus, mit zusätzlicher freiberuflicher Wochenbettbetreuung. Deutlich seltener wurde Schwangerenvorsorge auf freiberuflicher Basis angeboten. Hebammen, die ausschließlich freiberuflich arbeiteten, berichteten von mehr Kontinuität und einer Eins-zu-eins-Betreuung von Frauen bei der Geburt. Die Mehrheit arbeitete nach einem Modell, das keine Betreuungskontinuität oder eine konsequente Eins-zu-eins-Betreuung bot. Zukünftige Forschung sollte klären, ob sich Frauen in Deutschland mehr fallgebundene Eins-zu-eins-Betreuung von einer Hebamme wünschen.

\section{Introduction}

Each nation has a unique approach for maternity care with varying roles of midwives and obstetricians during pregnancy and labour [1-4]. In Germany, it is mandated by the federal law that midwives attend every woman's birth in the country, including caesarean births [5]. Registration of midwifery is nationalized, and there is only one legal certificate for midwives in Germany, which is the same regardless of practice location. Most midwives have a direct-entry certification, though a university education is becoming more prominent. Further, midwives with a nursing background before entering midwifery can acquire the certificate faster. In maternity units, only midwives provide intrapartum care for women. Labour and delivery nurses do not exist in Germany. Midwives play an integral part at every birth, regardless of birth mode and maternal risk profile. Obstetricians typically oversee most maternity units. In recent years, a number of midwife-led hospital units - where midwives independently manage and provide all care for low-risk women - emerged and have been in the public focus [4, 6, 7]. Midwives in Germany also practice in women's homes and free-standing birth centres. Out-of-hospital births represent approximately $1.3 \%$ of births in Germany [8].

Although every woman has to be attended by a midwife when giving birth, she does not necessarily see a midwife throughout pregnancy. The majority of women in Germany see obstetricians for antenatal care [9]. Only a few midwives are thought to offer the full range of antenatal care services, which is defined by the German code of social law (SGB V), section 24d [10]. Antenatally, midwives in Germany are known to provide selected services such as counselling, acupuncture and antenatal education. Midwives also commonly provide postpartum care including breastfeeding support, postnatal exercises and newborn care [10].
While each nation may approach maternity care differently, researchers have reached a high standard in identifying optimal models of midwifery care, which benefit women and their babies despite differences in customs and overarching health care systems $[4,11]$. For example, continuity of care by a midwife is associated with improved neonatal outcomes including fewer preterm births and admissions to neonatal intensive care units $[4,12,30]$. A recent review describes higher rates of spontaneous births in women receiving midwife-led continuity models of care, no difference in caesarean birth rates, and fewer intrapartum interventions like episiotomies, amniotomy and epidural analgesia [4]. When discerning differences among models of midwifery care, researchers may be able to discover what aspects of care allow midwives to achieve optimal birth outcomes $[12,13]$. For example, in midwifery-led models of care, an implicit philosophy of care trusting in the normality of labour may explain the reduced number of interventions [3].

In the last several decades, models of midwifery care have been described in the literature as personal caseload, shared caseload and team midwifery [4]. Intrapartum models include shared care, midwife-led care, and one-to-one care throughout labour and birth $[4,11,14-18]$. These models differ with respect to the level of the midwife's autonomy, employment pattern, continuity of care, place of birth as well as the type of collaboration with additional midwives and other health care professionals.

The caseload model evolved between 1990 and 2000 and describes continuous care for a defined caseload of women throughout pregnancy, birth and postpartum [19]. This model has been the focus of research for the past 15 years [14, 20-26] and is characterized by both high levels of continuity throughout the childbearing cycle, as well as autonomous midwifery management [19, 25, 27-29]. Caseload midwives usually meet pregnant adoles- 
cents earlier during pregnancy compared with standard care, which can reduce risk factors for preterm birth through adequate antenatal care [12]. Continuity of care in this model is associated with improved neonatal outcomes including fewer preterm births and admissions to neonatal intensive care units $[4,12,30]$. The literature demonstrates that caseload midwifery care is associated with improved maternal outcomes as well, including the reduced rate of obstetric interventions, birth mode [4, 18, 20, 31, 32], levels and forms of continuity [20,33-35], and women's satisfaction with the care they receive [6,36-39]. Women in a caseload model reported feeling a closer relationship to their midwife and could discuss concerns more freely $[6,40]$.

Increased continuity of care may also lead to increased maternal satisfaction [4]. Some studies found greater satisfaction with the overall birth experience [41] or with antenatal, intrapartum $[36,42]$ and postpartum [42] care with continuous care compared to standard care. Women also reported a higher feeling of control $[38,39,43]$ and a better ability to cope with labour $[4,41]$. There are contradictory findings regarding continuity of care and its association with maternal satisfaction $[37,44,45]$ but it remains of central interest for women choosing their midwifery care $[33,46]$.

Although the caseload model and continuity of care appear to have documented benefits for women and infants, it may not be the optimal model for midwives. The caseload model is associated with poor work-life balance and long work hours for midwives $[21,22,28,29,47,48]$. A major concern is burnout. Some researchers have addressed ways in which burnout might be reduced in caseload midwives [22,28], in part through strategies such as the provision of an additional midwife with a similar approach to care, working in a team, as well as self-care and maintenance of contact to friends and colleagues [22, 29, 47]. Additionally, the risk of burnout may be reduced by the inherent benefits of the caseload model such as satisfaction from developing relationships with women and increased autonomy in practice $[21,48]$.

Despite research interests in the organisation of midwifery services, there is no uniform international terminology for describing practice models [19]. As van Teijlingen [49] has noted, the concept of midwifery models of care is multifaceted. Midwives have used the term 'model of care' to refer to how midwifery care is conceptualized, idealized, or the aims it should achieve. It can also refer to the way services are organised. In our study, a model of care refers to the organisation of midwifery services and the associated values that underpin this organisation.

In German-speaking countries, midwifery care is widespread and yet there is very little peer-reviewed literature (in English or German) that describes or evaluates practice patterns in German midwifery care [50]. In Germany, midwifery is often characterized in terms of midwives' employment status: employed (angestellt) or independent (freiberuflich). Employment status affects the way midwives are paid and insured, as well as whether they work in shifts or on call. Employed midwives are paid and insured by the hospital for which they work, and are employed for shifts. Independent midwives, however, must cover their own indemnity insurance costs and are reimbursed for care through the National Association of Statutory Health Insurance Funds (GKV-Spitzenverband). Reimbursement from these insurances covers most of the services midwives offer, including antenatal care, postpartum vis- its and lactation support. Independent midwives are on call for their clients and usually travel with them to the birth location. Notably, indemnity insurance costs are often prohibitive and have been increasing, consequently restricting midwives' ability to practice independently [51, 52].

Because the provided model of midwifery care may affect the outcome of birth and maternal satisfaction, it is important to investigate which patterns of care are implemented in Germany. Although the dichotomy of employed and independent midwives is widely used to describe the forms of available midwifery working patterns in Germany, this classification alone cannot clarify the scope or philosophy of midwifery care, or the organisation of midwifery services.

Within and across the framework of employed and independent midwives, our study aimed to determine a more nuanced pattern through which care is provided in Germany by midwives who attend births, and to relate these patterns in an international context of midwifery models of care.

\section{Methods}

The study in the region of Hannover and Hildesheim, Germany, included 11 hospitals, ranging from small perinatal centres with over 1500 births per year to very small hospitals with around 500 births. There were also three free-standing birth centres managed by midwives in this area.

We conducted a cross-sectional survey of all midwives who attended births in $2009(n=211)$. The head midwives at all hospitals and free-standing birth centres provided counts of total midwives practicing at each location. A total of 24 midwives offering out-of-hospital birth in the Hannover and Hildesheim region were identified through the German Midwifery Association (DHV) listing for Lower Saxony. On the basis of telephone and/or email contact with each independent midwife, we found that 13 midwives attended births in the region in 2009. We excluded midwives who were not active in clinical practice, as well as midwives who did not provide any intrapartum care. Because there is no comprehensive list of active midwives in our region, we used the birth locations to identify our study participants. The smaller number of out-of-hospital midwives was located as noted above. We thus identified the following midwives attending births as a primary care provider in 2009: 182 were hospital employees, 5 worked as independent midwives in hospitals, 13 independently at home and 11 independently in birth centres.

Employed midwives were defined as those who were employed by the hospital for the intrapartum care they provided, even if they offered additional services on an independent basis for women in the community. We similarly defined independent midwives as those who were self-employed and provided intrapartum care autonomously, even if they were employed for other midwifery services. There was no overlap between the defined groups in this study regarding the status of the midwife either employed or practicing independently.

The survey was developed by the research team with feedback from practicing midwives in the region. The qualitative items were determined from themes in the literature on midwifery models of care. Because the survey mainly focussed on specific aspects of the 
working situation, no further item validation was performed. The survey and research protocol were approved by the Ethical Review Board of the Hannover Medical School (Nr. 634/2009). The study was exempt from full review by the board. Prior to administering the survey, it was distributed to midwives employed at the hospital affiliated with our research unit for review. We received and incorporated feedback regarding the clarity of study questions. We mailed and emailed surveys to the head midwives at the maternity units and free-standing birth centres, asking for consent to participate. Head midwives agreed to distribute and collect surveys from their colleagues. In addition, we mailed a survey to the home address of each home birth midwife, which was obtained from the professional listing with the German Midwives' Association. Follow-up phone calls were made to the head midwives at the maternity units and birth centres, as well as to each home birth midwife, in order to offer assistance with completing the survey, to encourage participation, and to clarify and/or contextualize responses. There was no compensation for participating.

The following variables were measured in the survey:

- scope of services provided by each midwife (including continuity of care)

- practice location

- employment pattern

- attitude towards core values of midwifery care.

Midwives rated the frequency with which they provided antenatal, intrapartum and postpartum care to the same women on a 5-point Likert scale from "never" to "almost always" [53]. We asked a separate question to determine how often midwives knew women prior to labour, because midwives also may have met them through classes, consultation, or additional services even if those midwives did not offer antenatal care to those women. The continuity of care during labour was assessed with another Likert scale question asking how often midwives provided one-to-one care during labour, defined as one midwife caring for a woman throughout her entire labour and birth. To address attitudes towards midwifery care and birth, midwives ranked the importance of the following aspects of care on a 5-point Likert scale, ranging from [1] very important to [5] unimportant: supporting women's choices during labour, establishing trust between woman and midwife, encouraging women's mobility in labour, viewing birth as a normal process, and knowing the woman before she presents in labour.

To determine if there were significant differences in practice patterns between employed and independent midwives, we compared the groups with the Chi-square test (for categorical variables) and Mann-Whitney U-test (for Likert-type attitude items). A p-value of less than 0.05 was considered significant.

\section{Results}

The response rate of the survey was $32.7 \%(n=69)$ for all midwives, $26.9 \%$ for hospital-employed midwives $(n=49)$, and $58.6 \%$ for independent midwives $(n=17)$. Midwives from all 11 hospitals and 3 birth centres responded. Three midwives did not indicate their employment status and were excluded from the analysis. For the analysis, this left a total of 66 responses (66/211, 32.3\%) from midwives in the region of Hannover and Hildesheim.
The majority of midwives who responded to the survey were employed by a hospital to provide intrapartum care $(74.2 \%, n=49)$, whereas a smaller number of respondents provided independent intrapartum care $(25.8 \%, \mathrm{n}=17)$. Among the latter, we received responses from midwives who provided intrapartum care in each of the three settings: hospital, birth centre and home.

The majority of surveyed midwives did not solely provide intrapartum care. Most of the surveyed midwives provided at least one independent service $(90.9 \%, n=60)$, regardless whether they were employed or independently working to provide intrapartum care. The most common respondent was thus an employed midwife who offered additional services on an independent basis. Overall these services included: antenatal care, childbirth education classes, postnatal care, lactation consulting, and postpartum exercises. Of both employed and independent midwives, the most provided postnatal care and breastfeeding consulting, and the fewest provided postpartum exercises ( $\triangleright$ Table $\mathbf{1}$ ).

However, there were differences between the services each group more often provided. Nearly all independent midwives provided antenatal care $(94.1 \%, \mathrm{n}=16)$, whereas less than half of employed midwives did so $(45.5 \%, n=44)$. Despite the finding that the two most commonly offered services of employed midwives included postpartum care and lactation consulting, significantly more independent midwives than employed midwives provided both services $(P<0.05$, > Table 1$)$.

Additional services were provided at a range of locations. A total of $98.3 \%(n=59)$ of midwives offered additional services in the same location they attended births, while $61.7 \%(n=37)$ of midwives stated they also provided services externally. The most common external location was the woman's home (reported by $56.3 \%$ of midwives).

Midwives had varying opportunities to engage with the same women through direct antenatal and postpartum care, or in providing additional services. Continuity of care was found to be associated with employment status. Compared to employed midwives, significantly more independent midwives provided antenatal and intrapartum care to the same woman, intrapartum and postpartum care, as well as all three services to the same woman $(p<0,001$, - Table 2). Independent midwives were significantly more likely to offer one-to-one care during labour and manage intrapartum care independent of an obstetrician ( $p<0.05$, $>$ Table 3 ). In addition, independent midwives were significantly more likely to know women before labour $(p<0.001)$. However, telephone contact with midwifery units provided additional information that further defined certain differences in care of hospital-employed midwives, as well as clarified that midwives at the free-standing birth centres provide care as a group. Although midwives in smaller hospitals were less likely to provide antenatal care to women they attended to in labour, they reported varied informal opportunities to meet their clients before labour. These opportunities included both provided services we investigated in this survey, as well as meeting the women while registering or touring the unit.

Midwifery attitudes we surveyed were largely similar. Most midwives across both groups found the support of choice, trust, women's mobility and normal birth to be "very" or "somewhat important" ( $\triangleright$ Table 4). On the other hand, more independent midwives than employed midwives found it important to know women be- 
- Table 1 Services Offered by Independent and Employed Midwives in Addition to Intrapartum Care.

\begin{tabular}{|c|c|c|c|c|c|}
\hline \multirow{2}{*}{$\begin{array}{l}\text { Did you offer the following } \\
\text { services in addition to } \\
\text { intrapartum care? }\end{array}$} & \multicolumn{2}{|c|}{ Employed a } & \multicolumn{2}{|c|}{ Independent ${ }^{b}$} & \multirow{2}{*}{$\begin{array}{c}\text { P values } \\
\text { (Chi-square) }\end{array}$} \\
\hline & n (\%) & M & n (\%) & M & \\
\hline Prenatal care & $\begin{array}{c}20(45.5) \\
(n=44)\end{array}$ & $n=5$ & $\begin{array}{c}16(94.1) \\
(n=17)\end{array}$ & $\mathrm{n}=0$ & $\mathrm{p}<0.001$ \\
\hline Childbirth education classes & $\begin{array}{c}19(39.6) \\
(n=48)\end{array}$ & $n=1$ & $\begin{array}{c}11(64.7) \\
(n=17)\end{array}$ & $\mathrm{n}=0$ & 0.07 \\
\hline Postnatal care & $\begin{array}{c}32(66.7) \\
(n=48)\end{array}$ & $\mathrm{n}=1$ & $\begin{array}{c}17(100) \\
(n=17)\end{array}$ & $\mathrm{n}=0$ & $\mathrm{p}<0.05$ \\
\hline Lactation consulting & $\begin{array}{c}28(58.3) \\
(n=48)\end{array}$ & $n=1$ & $\begin{array}{c}17(100) \\
(n=17)\end{array}$ & $\mathrm{n}=0$ & $\mathrm{p}<0.001$ \\
\hline Postpartum exercises & $\begin{array}{c}14(29.2) \\
(n=48)\end{array}$ & $n=1$ & $\begin{array}{l}9(52.9) \\
(n=17)\end{array}$ & $\mathrm{n}=0$ & 0.08 \\
\hline
\end{tabular}

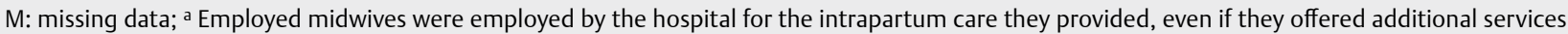
independently; ${ }^{b}$ Independent midwives were self-employed and provided intrapartum care autonomously, even if they were employed for other midwifery services.

- Table 2 Continuity of Prenatal, Intrapartum and Postpartum Care provided by Independent and Employed Midwives.

\begin{tabular}{|c|c|c|c|c|c|}
\hline \multirow{3}{*}{$\begin{array}{l}\text { How often did you provide the following } \\
\text { services to the same women? }\end{array}$} & \multicolumn{4}{|c|}{ Means from Likert scale ${ }^{a}$} & \multirow{3}{*}{$\begin{array}{c}\text { P-values } \\
\text { (Mann-Whitney U test) }\end{array}$} \\
\hline & \multicolumn{2}{|c|}{ Employed } & \multicolumn{2}{|c|}{ Independent } & \\
\hline & mean & M & mean & $\mathbf{M}$ & \\
\hline Prenatal and intrapartum care & $\begin{array}{c}1.72 \\
(n=47)\end{array}$ & $n=2$ & $\begin{array}{c}4.88 \\
(n=17)\end{array}$ & $\mathrm{n}=0$ & $p<0.001$ \\
\hline Intrapartum and postpartum care & $\begin{array}{c}2.25 \\
(n=48)\end{array}$ & $n=1$ & $\begin{array}{c}4.88 \\
(n=17)\end{array}$ & $n=0$ & $p<0.001$ \\
\hline Prenatal, intrapartum and postpartum care & $\begin{array}{c}1.74 \\
(n=47)\end{array}$ & $n=2$ & $\begin{array}{c}4.88 \\
(n=17)\end{array}$ & $\mathrm{n}=0$ & $\mathrm{p}<0.001$ \\
\hline
\end{tabular}

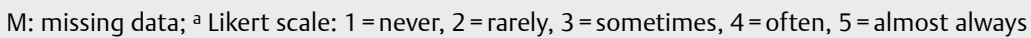

fore they presented for care in labour $(\mathrm{p}<0.001$, $>$ Table 4$)$. Both employed and independent midwives placed a high value on evidence-based and women-centred care. However, employed midwives were more likely to value time-efficient care $\left(X^{2}=10.608\right.$, $\mathrm{df}=1, \mathrm{p}=0.001)$ compared to independent midwives.

\section{Discussion}

We found that employment status of midwives providing intrapartum care was significantly associated with continuity of care, midwives' attitudes, and the care services provided, including antenatal care, postpartum care, and lactation consulting. The most common pattern of midwifery practice for midwives who provide intrapartum care in the region of Hannover was being employed at a hospital and working in shifts with additional services offered postpartum on an independent basis. A survey from a private re- search institute for health care and social services (IGES) showed an increasing proportion of midwives are offering independent midwifery services, rising from $75 \%$ of midwives in 2008 to $89 \%$ in 2011 [52]. However, the comparison is limited due to the low response rate to our survey, as well as our focus on those midwives who attend births. We also found that compared to the employed midwives, independent midwives were more likely to provide services to the same women throughout pregnancy and postpartum, to attend known women in labour, to offer one-to-one care, and manage intrapartum care independent of a physician.

Midwifery attitudes were relatively similar across both groups with regard to their high support of choice, trust, women's mobility and normal birth. These attitudes have been described as core values of the midwifery model of care $[15,35,54,55]$ and may transcend differences among models of care. We did find that employed midwives more often described their care as time-efficient. As em- 
- Table 3 Frequency of Variations of Intrapartum Midwifery Care in Independent and Employed Midwives' Practices.

\begin{tabular}{|c|c|c|c|c|c|}
\hline \multirow{3}{*}{$\begin{array}{l}\text { How often did you provide the } \\
\text { following care? }\end{array}$} & \multicolumn{4}{|c|}{ Means from Likert scale } & \multirow{3}{*}{$\begin{array}{c}\text { P-values } \\
\text { (Mann-Whitney U test) }\end{array}$} \\
\hline & \multicolumn{2}{|c|}{ Employed } & \multicolumn{2}{|c|}{ Independent } & \\
\hline & mean & M & mean & M & \\
\hline Provided intrapartum care to known woman & $\begin{array}{c}3.18 \\
(n=49)\end{array}$ & $\mathrm{n}=0$ & $\begin{array}{c}4.41 \\
(n=17)\end{array}$ & $\mathrm{n}=0$ & $p<0.001$ \\
\hline Provided one-to-one care ${ }^{b}$ & $\begin{array}{c}2.71 \\
(n=48)\end{array}$ & $n=1$ & $\begin{array}{c}5.00 \\
(n=17)\end{array}$ & $\mathrm{n}=0$ & $\mathrm{p}<0.001$ \\
\hline Provided midwife-led birthsc & $\begin{array}{c}1.80 \\
(n=46)\end{array}$ & $n=3$ & $\begin{array}{c}4.60 \\
(n=15)\end{array}$ & $\mathrm{n}=2$ & $p<0.001$ \\
\hline
\end{tabular}

M: missing data; ${ }^{a}$ Likert scale: 1 = never, 2 = rarely, 3 = sometimes, 4 = often, 5 = almost always; ${ }^{b}$ Defined as care by one midwife throughout the entire labour and birth; ' Defined as births where midwives provided care without the oversight of a physician.

- Table 4 Midwifery Attitudes Towards Intrapartum Midwifery Care.

\begin{tabular}{|c|c|c|c|c|c|}
\hline \multirow{3}{*}{$\begin{array}{l}\text { How important is it that a midwife does } \\
\text { the following? }\end{array}$} & \multicolumn{4}{|c|}{ Means from Likert scale ${ }^{a}$} & \multirow{3}{*}{$\begin{array}{c}\text { P-values } \\
\text { (Mann-Whitney U test) }\end{array}$} \\
\hline & \multicolumn{2}{|c|}{ Employed } & \multicolumn{2}{|c|}{ Independent } & \\
\hline & mean & $\mathbf{M}$ & mean & $\mathbf{M}$ & \\
\hline Supports informed decisions & $\begin{array}{c}4.41 \\
(n=46)\end{array}$ & $n=3$ & $\begin{array}{c}4.71 \\
(n=17)\end{array}$ & $\mathrm{n}=0$ & 0,06 \\
\hline Supports woman's mobility in labour/birth & $\begin{array}{c}4.56 \\
(n=45)\end{array}$ & $\mathrm{n}=4$ & $\begin{array}{c}4.82 \\
(n=17)\end{array}$ & $\mathrm{n}=0$ & 0,12 \\
\hline Views birth as a normal process & $\begin{array}{c}4.83 \\
(n=47)\end{array}$ & $n=2$ & $\begin{array}{c}5.00 \\
(n=17)\end{array}$ & $\mathrm{n}=0$ & 0,10 \\
\hline Establishes trust with the labouring woman & $\begin{array}{c}4.96 \\
(n=47)\end{array}$ & $n=2$ & $\begin{array}{c}4.88 \\
(n=17)\end{array}$ & $\mathrm{n}=0$ & 0,28 \\
\hline Knows the woman before labour & $\begin{array}{c}3.34 \\
(n=47)\end{array}$ & $n=2$ & $\begin{array}{c}4.41 \\
(n=17)\end{array}$ & $\mathrm{n}=0$ & $\mathrm{p}<0,001$ \\
\hline
\end{tabular}

M: missing data; a Likert scale: 1 = unimportant, 2 = somewhat important, $3=$ neutral, 4 = important, $5=$ very important

ployed midwives all practiced in the hospital setting in Germany, this finding could be influenced by their practice environment, where several labouring women were attended at the same time, midwives worked in shifts, and hospital protocols were standardized and dictated care practices. Additionally, independent midwives found it more important to know women before they present for care in labour; a finding that is not surprising given that independent midwives were more likely to know the women during pregnancy by providing antenatal care.

Hospital-employed midwives were less likely to provide antenatal and intrapartum care to the same women. However, in small hospitals midwives had opportunities to meet women before labour when they came for antenatal care, classes, or acupuncture treatment. Hence, even though there seems to be less frequent continuous care offered by employed midwives, many were still able to offer an ongoing relationship due to the size of their employing hospital or additional services. In contrast, independent midwives almost always provided continuity of care from antenatal visits to postpartum.

When considering this continuity in the context of international literature on models of care, it cannot be assumed that independent midwives all offered the equivalent of personal caseload care, where a midwife has a personal caseload of women for whom she is individually responsible. In telephone conversations, midwives at the free-standing birth centres reported providing care as a group, which is comparable to known shared caseload models, 
where women met several midwives through the course of their antenatal care, and were likely to know their midwife at labour but not guaranteed to, depending on the practice size [15].

There were other differences among the midwives, such as practice setting. Some independent midwives worked with a caseload of women and provided intrapartum care in the hospital setting (Beleghebammen). Others worked with a personal caseload and provided intrapartum care in homes (Hausgeburtshebammen).

In many countries, midwives are care providers who practice as an alternative to physician care [56]. In Germany, midwives' intrapartum role is legislated and ubiquitous [5]. However, midwives' roles outside of intrapartum care are more open to variation. Thus, the combination of consultant-led antenatal care with midwife-attended birth that we anticipated to be most common was supported by our findings that most midwives did not offer antenatal care. However, our findings indicate that many midwives are involved antenatally and postpartum by offering multiple services even when they are employed for intrapartum care. Among the midwives who provided antenatal care, this could indicate that obstetricians and midwives provide shared care, both billing for these services. Additionally, midwives could be providing education and counselling services while obstetricians bill for medical care.

We used intrapartum care as the starting point for our study, but there are midwives in Germany who do not provide intrapartum care and solely provide antenatal care, childbirth education, postpartum care and lactation consultation. These services are covered by German public insurance. From our study and in the opinion of the study authors, midwives in Germany appear to have very diverse practice patterns. This could be enabled by the single license needed to practice midwifery along with the reimbursement for many midwife-provided services by German public health insurance [10]. Further investigation is required regarding the work of midwives who are not actively attending births but provide other maternity care services.

Employed midwives in our study had heterogeneous practices in which they offered many additional services, most often at either the same institution or in women's homes postpartum. Nevertheless, only independent midwives offered out-of-hospital birth services. As such, independent midwifery can be associated with choice of birth setting. This variation of practices leads to the conclusion that while independent midwifery and employed midwifery describe employment relations rather than models of midwifery care, they have considerable impact on the ability of midwives to provide different models of care, as well as care in different settings. Only independent midwives offered services in a caseload care-like model and offered out-of-hospital birth services.

The diversity of practice within each employment relation is a limitation of our small-scale study because it diminishes the relevance of these categories used in our analysis. Additional limitations include the overall low response rate and further, that proportionally more independent midwives responded than employed midwives. Moreover, midwives who offer postpartum and antenatal care but do not attend birth were excluded from the study due to our focus on intrapartum care and midwifery services that were offered additionally. This presents another limitation, because these midwives provide care with high preventative value for mother and child $[57,58]$.
The cited limitations thus reduce the generalizability of our findings to all midwives practicing in Germany. Due to the explorative nature of this small-scale study, we were not yet able to investigate what aspects of midwifery models might allow for differences in outcomes. This is a major aspect that should be considered in future research.

Despite the limitations in focusing on employment status, the patterns of care offered by independent midwives-providing services to the same women throughout pregnancy and postpartum, attending known women in labour, and offering one-to-one care throughout labour and birth-along with the belief in women-centred care, are comparable to the caseload model of care $[4,15,19]$. Along with continuity, caseload care entails a high degree of autonomy in midwifery care $[22,28,29,39]$. Independent midwives were more likely to report practicing independent of a physician. Future research is needed to identify links between existing practice patterns, models of care and outcomes, both in Germany and internationally.

In addition, midwife-led continuity models of care are associated with increased maternal satisfaction, which also indicates that various modifications of the continuity model increase satisfaction [4]. In turn, increased maternal satisfaction has been associated with both a reduction in interventions and increase in women's control, indicating that models of care should be a topic of further research $[37,39,43]$.

Importantly, it is also clear that there are barriers to caseload midwifery practice models from the perspective of international midwives [11, 21, 22, 28, 29, 47, 59], which could also explain the lack of defined caseload midwifery working patterns in the Hannover region. Caseload midwives have to cope with the challenge of being on call, working long hours and being primary care providers, [21, 22, 28, 29, 47, 48]. The employment status might also affect the satisfaction of midwives. Independent midwives in Germany, who manage their practice, encounter the additional stress and challenges of running their own business. They may not have had professional training in business management. In addition, employment status affects the indemnity insurance a midwife has to pay and thus is a critical part of the financial and legal aspects of her care. Indemnity insurance costs can make a practice financially unfeasible [47] and currently represents a significant barrier to independent midwifery practice in Germany [10, 51, 52]. For midwives, being able to provide care in a caseload model as an employed midwife, instead of on a freelance basis, might be desirable as presented by Tracy et al. [11]. In fact, the German Society of Perinatal Medicine (DGPM) recommends one-to-one continuous care during labour [60].

The link between maternal satisfaction, clinical outcome, and midwifery practice patterns with and without continuity of care should be a future priority for research [61-63]. Although our small-scale study did not investigate outcomes associated with working patterns of care, we identified that the organisation of midwifery services relates to important factors including continuity of care and midwifery attitudes. Hence, our research points to a trusting relationship between women and midwives, including the perspectives of our participants. Exploring working patterns or even models of midwifery care in established settings allows researchers to look at what paths women take through maternity 
care, and what organisational patterns or models allow for - and encourage - optimal midwifery care and maternal and neonatal outcomes.

\section{Acknowledgements}

We would like to thank all the midwives participating in the survey, especially Gitta Scholz for commenting on previous drafts.

\section{Conflict of Interest}

The authors declare that they have no conflict of interest.

\section{References}

[1] ten Hoope-Bender P, de Bernis L, Campbell J et al. Improvement of maternal and new born health through midwifery. Lancet 2014; 384: 1226-1235

[2] Renfrew M], McFadden A, Bastos MH et al. Midwifery and quality care: findings from a new evidence-informed framework for maternal and newborn care. Lancet 2014; 384: 1129-1145

[3] Soltani H, Sandall J. Organisation of maternity care and choices of mode of birth: a worldwide view. Midwifery 2012; 28: 146-149

[4] Sandall J, Soltani H, Gates $S$ et al. Midwife-led continuity models versus other models of care for childbearing women. Cochrane Database Syst Rev 2016; 4: CD004667

[5] HebG- Hebammengesetz. "Gesetz über den Beruf der Hebamme und des Entbindungspflegers" [Law of the midwife profession], Bundesgesetzblatt I [Federal Law Gazette I], p. 902 (BGBI. I S. 902): Hebammengesetz vom 4. Juni 1985, das durch Artikel 17b des Gesetzes vom 23. Dezember 2016 (BGBI. I S. 3191) geändert worden ist [Law of midwife profession from June 4th 1985 changed by paragraph 17b of the Federal Law Gazette I, p. 983 (BGBI. I S. 3191) on December 23rd 2016.] Available from: http://www.gesetze-im-internet.de/hebg_1985/BJNR009020985.html ; 1985 [Accessed 30th of January 2017]

[6] Beake S, Acosta L, Cooke P et al. Caseload midwifery in a multi-ethnic community: the women's experiences. Midwifery 2013; 29: 996-1002

[7] Rahden von O. Der Hebammenkreißsaal: Eine geburtshilfliche Alternative. IPP Info 2006; 2: 9

[8] QUAG. Gesellschaft für Qualität in der außerklinischen Geburtshilfe e.V. Qualitätsbericht 2015. The website of the Association for Quality in Out-of-hospital Births: http://www.quag.de/downloads/QUAG_bericht2015.pdf ; 2015 [Accessed February 1, 2017]

[9] Bundesausschuss der Ärzte und Krankenkassen. (2016) Richtlinien des Bundesausschusses der Ärzte und Krankenkassen über die ärztliche Betreuung während der Schwangerschaft und nach der Entbindung (Mutterschafts-Richtlinien) in der Neufassung vom 10. Dez. 1985. Zuletzt geändert am 21. April 2016; veröffentlicht im Bundesanzeiger AT 19.07.2016 B5; https://www.g-ba.de/downloads/62-492-1223/ Mu-RL_2016-04-21_iK-2016-07-20.pdf [Accessed October 15, 2017]

[10] GKV Spitzenverband. 2015b. Hebammenhilfevertrag § 134a Abs. 1 SGB V in der Fassung des Schiedsspruches (Social Security Code book 5 version of arbitral award). Online available: https://www. gkv-spitzenverband.de/media/dokumente/krankenversicherung_1/ ambulante_leistungen/hebammen/aktuelle_dokumente/Hebammen_ Vertrag_nach__134a_SGB_V_in_der_Fassung_des Schiedsspruchs_2015.pdf; 2015 [Accessed August 25, 2016]
[11] Tracy SK, Hartz DL, Tracy MB et al. Caseload midwifery care versus standard maternity care for women of any risk: M@NGO, a randomised controlled trial. Lancet 2013; 382: 1723-1732

[12] Allen J, Kildea S, Stapleton H. How optimal caseload midwifery can modify predictors for preterm birth in young women: Integrated findings from a mixed methods study. Midwifery 2016; 41: 30-38

[13] Kennedy HP. A model of exemplary midwifery practice: results of a Delphi study. J Midwifery Womens Health 2000; 45: 4-19

[14] Johnson M, Stewart H, Langdon R et al. A comparison of the outcomes of partnership caseload midwifery and standard hospital care in low risk mothers. Aust J Adv Nurs 2005; 22: 21-27

[15] McCourt C, Stevens T, Sandall J et al. Working with women: developing continuity of care in practice. In: Page LA, McCandlish R. (Ed.) The New Midwifery: Science and Sensitivity in Practice. 2nd ed.The Netherlands: Elsevier Limited; 2006: 141

[16] McCourt C, Rayment J, Rance S et al. An ethnographic organisational study of alongside midwifery units: a follow-on study from the Birthplace in England programme. Southampton (UK): NIHR Journals Library; 2014

[17] Scupholme A. Nurse-midwives and physicians: a team approach to obstetrical care in a perinatal center. J Nurse Midwifery 1982; 27: 21-27

[18] Wilkes E, Gamble J, Adam G et al. Reforming maternity services in Australia: Outcomes of a private practice midwifery service. Midwifery 2015; 31: 935-940

[19] Hartz DL, Foureur M, Tracy SK. Australian caseload midwifery: the exception or the rule. Women Birth 2012; 25: 39-46

[20] Benjamin Y, Walsh D, Taub N. A comparison of partnership caseload midwifery care with conventional team midwifery care: labour and birth outcomes. Midwifery 2001; 3: 234-240

[21] Collins CT, Fereday J, Pincombe J et al. An evaluation of the satisfaction of midwives' working in midwifery group practice. Midwifery 2010; 26: 4435-4441

[22] Jepsen I, Mark E, Nøhr EA et al. A qualitative study of how caseload midwifery is constituted and experienced by Danish midwives. Midwifery 2016; 36: 61-69

[23] North Staffordshire Changing Childbirth Research Team. A randomised study of midwifery caseload and traditional 'shared care'. Midwifery 2000; 16: 295-302

[24] Leap N, Sandall J, Buckland S et al. Journey to confidence: women's experiences of pain in labour and relational continuity of care. J Midwifery Womens Health 2010; 55: 234-242

[25] Lee Davis D, Walker K. Case-loading midwifery in New Zealand: bridging the normal/abnormal divide 'with woman'. Midwifery 2011; 27: $46-52$

[26] Freeman LM. Continuity of carer and partnership: A review of the literature. Women Birth 2006; 19: 39-44

[27] McCourt C. Supporting choice and control? Communication and interaction between midwives and women at the antenatal booking visit. Soc Sci Med 2006; 62: 1307-1318

[28] Newton MS, McLachlan HL, Willis KF et al. Comparing satisfaction and burnout between caseload and standard care midwives: findings from two cross-sectional surveys conducted in Victoria, Australia. BioMedCentral Pregnancy Childbirth 2014; 24: 426

[29] Newton MS, McLachlan HL, Forster DA et al. Understanding the 'work' of caseload midwives: A mixed-methods exploration of two caseload midwifery models in Victoria, Australia. Women Birth 2016; 29: 223-233

[30] Allen J, Gibbons K, Beckmann M et al. Does model of maternity care make a difference to birth outcomes for young women? A retrospective cohort study. Int J Nurs Stud 2015; 52: 1332-1342 
[31] Jackson D], Lang JM, Swartz WH et al. Outcomes, safety, and resource utilization in a collaborative care birth center program compared with traditional physician-based perinatal care. Am J Public Health 2003; 93: 999-1006

[32] Turnbull D, Baghurst P, Collins $C$ et al. An evaluation of Midwifery Group Practice. Part I: clinical effectiveness. Women Birth 2009; 22: 3-9

[33] Brintworth K, Sandell J. What makes a successful home birth service: An examination of the influential elements by review of one service. Midwifery 2013; 29: 713-721

[34] Hollowell J, Rowe R, Townend J et al. The Birthplace in England national prospective cohort study: further analyses to enhance policy and service delivery decision-making for planned place of birth. Southampton (UK): NIHR Journals Library; 2015

[35] Symon A, Pringle J, Cheyne $\mathrm{H}$ et al. Midwifery-led antenatal care models: mapping a systematic review to an evidence-based quality framework to identify key components and characteristics of care. BMC Pregnancy Childbirth 2016; 16: 168

[36] Biró MA, Waldenström U, Brown S et al. Satisfaction with team midwifery care for low- and high-risk women: a randomized controlled trial. Birth 2003; 30: 1-10

[37] Farquhar M, Camilleri-Ferrante C, Todd C. Continuity of care in maternity services: women's views of one team midwifery scheme. Midwifery 2000; 16: 35-47

[38] Spurgeon P, Hicks C, Barwell F. Antenatal, delivery and postnatal comparisons of maternal satisfaction with two pilot Changing Childbirth schemes compared with a traditional model of care. Midwifery 2001; 17: 123-132

[39] Williams K, Lago L, Lainchbury A et al. Mothers' views of caseload midwifery and the value of continuity of care at an Australian regional hospital. Midwifery 2010; 26: 615-621

[40] Davison C, Hauck YL, Bayes SJ et al. The relationship is everything: Women's reasons for choosing a privately practising midwife in Western Australia. Midwifery 2015; 31: 772-778

[41] McLachlan H, Forster D, Davey M et al. Effects of continuity of care by a primary midwife (caseload midwifery) on caesarean section rates in women of low obstetric risk: the COSMOS randomised controlled trial. Br J Obstet Gynaecol 2012; 119: 1483-1492

[42] Forster DA, McLachlan HL, Davey MA et al. Continuity of care by a primary midwife (caseload midwifery) increases women's satisfaction with antenatal, intrapartum and postpartum care: results from the COSMOS randomised controlled trial. BioMedCentral Pregnancy Childbirth 2016; 3: 28

[43] Fair CD, Morrison TE. The relationship between prenatal control, expectations, experienced control, and birth satisfaction among primiparous women. Midwifery 2012; 28: 39-44

[44] Green JM, Renfrew MJ, Curtis PA. Continuity of carer: what matters to women? A review of the evidence. Midwifery 2000; 16: 186-196

[45] Fereday J, Collins C, Turnbull D et al. An evaluation of midwifery group practice. Part II: women's satisfaction. Women Birth 2009; 22: 11-16

[46] Hollowell J, Li Y, Malouf R et al. Women's birth place preferences in the United Kingdom: a systematic review and narrative synthesis of the quantitative literature. BioMedCentral Pregnancy Childbirth 2016; 16: 213

[47] Fereday J, Oster C. Managing a work-life balance: the experiences of midwives working in a group practice setting. Midwifery 2010; 26: $311-318$
[48] Gu C, Zhang Z, Ding D. Chinese midwives' experience of providing continuity of care to labouring women. Midwifery 2011; 27: 243-249

[49] Teijlingen van E. A critical analysis of the medical model as used in the study of pregnancy and childbirth. Sociol Res Online 2005; 2: 10

[50] Stone NI. Making physiological birth possible: birth at a free-standing birth centre in Berlin. Midwifery 2012; 28: 568-575

[51] GKV-Spitzenverband. 2015; Pressemitteilung: Verbindliche Qualitätskriterien für Hausgeburten, Lösung für Haftpflichtproblematik, fünf Prozent Honorarsteigerung (Mandatory quality criteria for home births, solution for the liability problem, five percent increase in fee); https://www.gkvspitzenverband.de/media/dokumente/presse/ pressemitteilungen/2015_1/PM_2015_09_28_Hebammen_Qualitaet_Hausgeburten.pdf. [Accessed March 30, 2016]

[52] IGES Institute. Bestandsaufnahme: Gutachten zeigt Versorgungsrealität in der Hebammenhilfe (Inventory: Expertise shows reality of care in midwifery help); 2012

[53] Likert R. A technique for the measurement of attitudes. Archives of Psychology 1932; 140: 1-55

[54] McLachlan HL, Forster DA, Davey M et al. Cosmos: comparing standard maternity care with one-to-one midwifery support: a randomised controlled trial. BioMedCentral Pregnancy Childbirth 2008; 8: 35

[55] Rawnson S. A qualitative study exploring student midwives' experiences of carrying a caseload as part of their midwifery education in England. Midwifery 2011; 27: 786-792

[56] Grünebaum A, McCullough LB, Arabin B et al. Neonatal mortality of planned home birth in the United States in relation to professional certification of birth attendants. PLOS ONE 2016; 11: e0155721

[57] Grylka-Baeschlin S, van Teijlingen E, Stoll K et al. Translation and validation of the German version of the Mother-Generated Index and its application during the postnatal period. Midwifery 2015; 31: 1 47-53

[58] MacArthur C, Winter HR, Bick DE et al. Redesigning postnatal care: a randomised controlled trial of protocol-based midwifery-led care focused on individual women's physical and psychological health needs. Health Technol Assess 2003; 7: 371-398

[59] Todd C], Farquhar MC, Camilleri-Ferrante C. Team midwifery: the views and job satisfaction of midwives. Midwifery 1998; 14: 214-224

[60] DGPM. 2015; S1-Leitlinie 087-001. Deutsche Gesellschaft für Perinatale Medizin: Empfehlungen für die strukturellen Voraussetzungen der perinatologischen Versorgung in Deutschland (German Society for Perinatal Medicine: Guidelines for structural requirements of perinatal care in Germany). Online available: http://www.awmf.org/ uploads/tx_szleitlinien/087-001I_S1_Perinatologische_Versorgung_2015-05.pdf; 2015 [Accessed at August 24, 2016].

[61] Carter AG, Wilkes E, Gamble J et al. Midwifery students' experiences of an innovative clinical placement model embedded within midwifery continuity of care in Australia. Midwifery 2015; 31: 765-771

[62] Hildingsson I, Karlström A, Haines $\mathrm{H}$ et al. Swedish women's interest in models of midwifery care - Time to consider the system? A prospective longitudinal survey. Sexual \& Reproductive Health Care 2016; 7: 27-32

[63] Wong N, Browne J, Ferguson S et al. Getting the first birth right: A retrospective study of outcomes for low-risk primiparous women receiving standard care versus midwifery model of care in the same tertiary hospital. Women and Birth 2015; 28: 279-284 


\title{
Intrapartum Care Working Patterns of Midwives: The Long Road to Models of Care in Germany
}

\author{
Authors \\ Mechthild M. Gross ${ }^{1}$, Claire Michelsen¹, Bernhard Vaske², Sonja Helbig1 \\ Affiliations \\ 1 Midwifery Research and Education Unit, Hannover Medical School, Hannover, Germany \\ 2 Institute for Biostatistics, Hannover Medical School, Hannover, Germany
}

Objective Optimally organising midwifery models of care helps to enhance maternal and neonatal health outcomes, women's satisfaction, and continuity of care. Despite the ubiquitous presence of certified midwives at births in Germany, no research has investigated the diversity of midwives' practice patterns. In Germany, midwifery is often characterized in terms of midwives' employment status: employed or independent. However this characterization does not correlate with international literature on midwifery models of care. Describing the variety of working patterns through which midwives provide intrapartum care in relation to ancillary midwifery services may contribute to improving the organisation of midwifery services in Germany.

Methods We conducted a cross-sectional survey of midwives who attended births in and out-of-hospital in the regions of Hannover and Hildesheim, Germany. Midwives who did not attend births were excluded.

Measurements and findings We assessed midwives' scope of services, practice locations, employment patterns, continuity of care, midwife-led births, and midwives' level of agreement with core values of midwifery care. The response rate of the survey was $32.7 \%$ (69/211). We found that midwifery care services can be described according to midwives' employment patterns. The majority of midwives who responded were employed in a hospital to provide intrapartum care $(74.2 \%, n=49)$. Only $25.8 \%(n=17)$ of midwives provided intrapartum care independently. Most of the surveyed midwives provided at least one additional independent service ( $90.9 \%, n=60)$, regardless whether they were employed or independently working to provide intrapartum care. The most common services provided were postnatal care and lactation consulting. However, there were differences in the care provided by indepen- dent and employed midwives. Significantly more independent midwives than employed midwives offered lactation consulting and antenatal care. Compared to employed midwives, significantly more independent midwives provided antenatal, intrapartum, and postpartum care to the same women, were more likely to know women before labour, and to offer one-to-one care during labour. Furthermore, independent midwives attended births in all three possible settings: hospital, free-standing birth centres and home. Most midwives valued women's choice, trust, mobility in labour, and normal birth.

Key conclusions and implications for practice The most common practice pattern among surveyed midwives was 'employment in a hospital' for provision of intrapartum care with additional postpartum and few antenatal services provided on an independent basis. Many employed midwives provided additional services to women, but few provided prenatal care. Midwives who worked solely independently reported more continuity and one-to-one intrapartum care with women. In the international literature, caseload models with high continuity and midwifery autonomy are consistently associated with improved maternal and neonatal outcomes. However, most midwives in Germany did not work in patterns that provided continuity of care or consistently offered one-to-one care. Additionally, independent midwives are the only midwives who offered care in out-of-hospital settings. Future research should assess whether women in Germany desire more services similar to caseload midwifery, and whether midwives in Germany would be willing and able to provide these services due to the rising indemnity insurance costs associated with independent midwifery.

This condensed content relates to a full article published in „Zeitschrift für Geburtshilfe und Neonatologie“. Please quote the original publication as follows: Z Geburtshilfe Neonatol DOI: $10.1055 / \mathrm{s}-0043-122888$ 